11. CONTROL OF EMISSIONS FROM NEW AND IN-USE NONROAD COMPRESSION-IGNITION ENGINES: Code of Federal Regulations. Title 40, part 1039. - Текст электронный // Electronic Code of Federal Regulations. - URL: https://www.ecfr.gov/cgi-bin/text-idx?mc=true\&node=pt40.36.1039\&rgn=div5 (Дата обращения: 08.07.2020).

12. ГОСТ Р 41.96-2011 (Правила ЕЭК ООН №96) Единообразные предписание, касающиеся двигателей с воспламенением от сжатия, предназначенных для установки на сельскохозяйственных и лесных тракторах и внедорожной технике, в отношении выброса вредных веществ этими двигателями. Текст электронный // Консорциум КОДЕКС. Электронный фонд правовой и нормативнотехнической документации: офиц. сайт. - URL: http://docs.cntd.ru/document/1200094453. (Дата обращения 8.07.2020).

13. Хачиян А.С., Морозов К.А., Луканин В.Н. Двигатели внутреннего сгорания: Учеб. для вузов / Под ред. Луканина В.Н. - 2-е изд., перераб и доп. - М.: Высш. шк., 1985. - 311 с.

14. Алексеев В.П., Воронин В.Ф., Грехов Л.В. Двигатели внутреннего сгорания. Устройство и работа поршневых и комбинированных двигателей / Под общ. ред. А.С. Орлина, М.Г. Круглова. - 4-е изд., перераб. и доп. - М.: Машиностроение, 1990. -283 с.: ил.

15. Круглов М.Г., Меднов А.А. Газовая динамика комбинированных двигателей внутреннего сгорания: учеб. пособие для вузов. - М.: Машиностроение, 1988. - 360 с.

16. Горбунов В.В., Патрахальцев Н.Н. Токсичность двигателей внутреннего сгорания: учеб. Пособие для вузов. - М.: Изд-во РУДН, 1998. - 214 с.

17. Гаврилов А.А. Агрегаты наддува: курс лекций для студентов ВлГУ. - Владимир, 2016. - 133 с.

\title{
ИССЛЕДОВАНИЕ ПРОЦЕССОВ ИЗМЕНЕНИЯ РУДНИЧНОЙ АТМОСФЕРЫ ДЛЯ ОПРЕДЕЛЕНИЯ ПРИЧИН ПРОИЗОШЕДШЕГО ГРУППОВОГО НЕСЧАСТНОГО СЛУЧАЯ НА ОДНОМ ИЗ РУДНИКОВ РФ
}

\author{
Л.Ю. Левин, Д.С. Кормщиков, Е.Л. Гришин \\ Горный институт УрО РАН, г. Пермь
}

\begin{abstract}
Аннотация: В работе представлены результаты натурных и теоретических исследований рудничной атмосферы и происходящих в ней аэрологических процессов на одном из рудников РФ в месте происшествия группового несчастного случая, связанного с окислением сульфидных руд. Произведены натурные измерения фактического качественного состава воздуха после происшествия, его микроклиматических параметров. Отобраны и обработаны пробы воздуха для определения качественного состава и анализа жизнедеятельности бактерий. Произведено трехмерное моделирование процесса проветривания горной выработки - места несчастного случая.

Ключевые слова: рудничная вентиляция, окисление сульфидных руд, тупиковые выработки, математическое моделирование, ядовитые газы.
\end{abstract}

\section{Введение}

В октябре 2019 года на одном из рудников РФ произошел групповой несчастный случай со смертельным исходом: в результате удушения произошла гибель троих работников предприятия. Несчастный случай произошел в транспортном заезде в камеру. В результате закладки очистного пространства камеры после окончания ее отработки образовалась непроветриваемая тупиковая выработка, имеющая уклон и большую протяженность (〉 10 м). Большая часть выработки пройдена во вмещающих породах, тупиковая часть выработки располагается непосредственно в рудном теле, контакт с породным массивом представлен сульфидными рудами, почва выработки покрыта рудным штыбом.

Специалисты ГИ УрО РАН приняли участие в расследовании причин произошедшего в качестве экспертов. Исследования разбиты на две стадии: 
- натурная часть с выездом специалистов на место несчастного случая;

- исследовательская часть, проведенная с применением необходимого оборудования в ПФИЦ УрО РАН.

Целью исследования являлось выявление причины произошедшего несчастного случая и приведших к ней обстоятельств.

\section{Описание проведенных исследований}

Натурная часть включила в себя измерения микроклиматических параметров атмосферы горной выработки, в которой произошел несчастный случай, тепловизионную съемку поверхностей выработки, отбор проб воздуха для определения качественного состава, отбор образцов горных пород и рудного штыба, отбор проб шахтной воды.

Исследовательская часть включила в себя трехмерное численное моделирование проветривания места несчастного случая, обработку и анализ проб шахтного воздуха и воды, минералогические исследования образцов горных пород, бактериологические исследования привезенных образцов горных пород, воздуха и воды.

\section{Результаты исследования параметров атмосферы горной выработки}

В результате посещения места происшествия были произведены натурные исследования параметров рудничной атмосферы и взяты пробы рудничного воздуха с их последующей обработкой на хроматографе для определения качественного состава.

Места замеров представлены на плане-схеме места происшествия (рисунок 1). Место обнаружения пострадавших обозначено красным цветом (позиция 2).

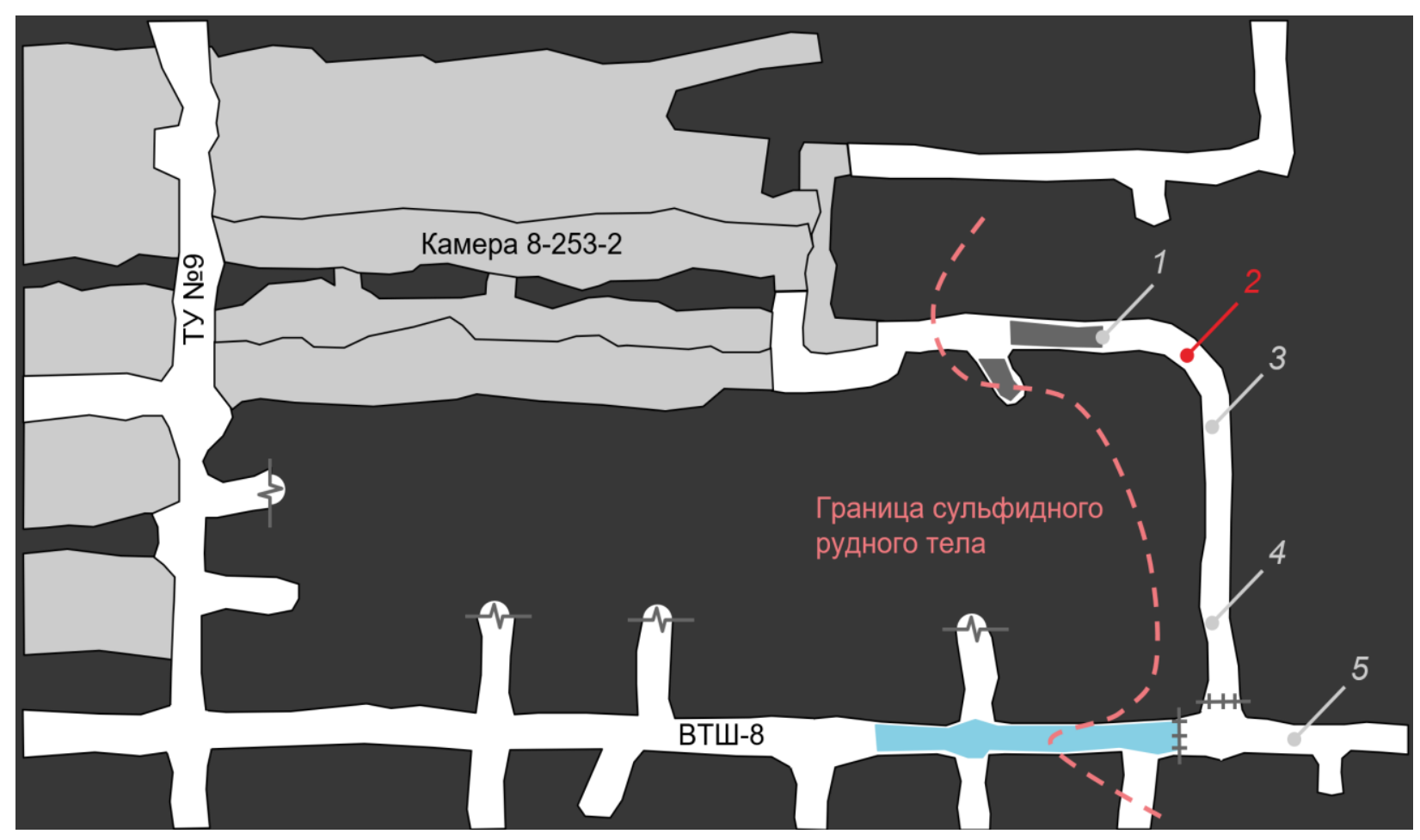

Рис. 1. План-схема места происшествия

Результаты исследования проб воздуха на качественный анализ, а также результаты исследования микроклиматических параметров воздуха и тепловизионной съемки представлены в таблице 1. 
Параметры рудничной атмосферы в районе происшествия

Таблица 1

\begin{tabular}{|c|l|c|c|c|c|c|c|c|}
\hline \multirow{2}{*}{$\begin{array}{c}\text { № } \\
\text { п/п }\end{array}$} & \multicolumn{1}{|c|}{ Место отбора проб } & \multicolumn{4}{|c|}{ Содержание газа, \% по объему } & \multicolumn{2}{c|}{$\begin{array}{c}\text { Температура, } \\
\text { ' } \mathbf{C}\end{array}$} \\
\cline { 3 - 9 } & & $\mathrm{O}_{2}$ & $\mathrm{CO}_{2}$ & $\mathrm{SO}_{2}$ & $\mathrm{CO}$ & $\mathrm{H}_{2} \mathrm{~S}$ & $\begin{array}{c}\text { Во3- } \\
\text { духа }\end{array}$ & $\begin{array}{c}\text { Мас- } \\
\text { сива }\end{array}$ \\
\hline 1 & У тупика (завала) & 2,6 & 0,25 & 0,0000228 & 0,000595 & 0 & 34 & 29 \\
\hline 2 & Место несчастного случая & 2,6 & 0,2 & 0,0000304 & 0,000510 & 0 & 34 & 29 \\
\hline 3 & У поворота на выработке Т3 №2 & 8,9 & 0,19 & 0,0000228 & 0,000680 & 0 & 33 & 27 \\
\hline 4 & $\begin{array}{l}\text { В пяти метрах от сопряжения с } \\
\text { выработкой ВТШ-8/Т3 №3 }\end{array}$ & 20,1 & 0,09 & 0,0000076 & 0 & 0 & 32 & 26 \\
\hline 5 & $\begin{array}{l}\text { В выработке ВТШ-8/Т3 №3 по- } \\
\text { сле сопряжения с Т3 №2 }\end{array}$ & 20,9 & 0,05 & 0 & 0 & 0 & 25 & 25 \\
\hline
\end{tabular}

Полученные результаты исследований показывают, что содержание ядовитых газов в выработке не превышают ПДК [1], при этом содержание сернистого газа составляет $10 \%$ от ПДК, а сероводород не обнаружен.

Однако температуры поверхности рудного тела и температуры воздуха в горной выработке превышают фоновые значения для района месторасположения и относительно соседних выработок. Это является индикатором наличия окислительных процессов, происходящих в выработке.

\section{Результаты исследования процесса проветривания места несчастного случая}

Натурные исследования показали отсутствие уловимого приборами движения воздуха в тупиковой части выработки. Однако современные измерительные приборы имеют ограничения чувствительности и не способны обнаруживать все процессы перемешивания воздуха в рудничной атмосфере. Наличие данного инструментального ограничения потребовало разработки численной модели тупиковой выработки и проведения численных расчетов движения воздуха в горной выработке, где произошел несчастный случай. Результаты моделирования представлены на рисунке 2.

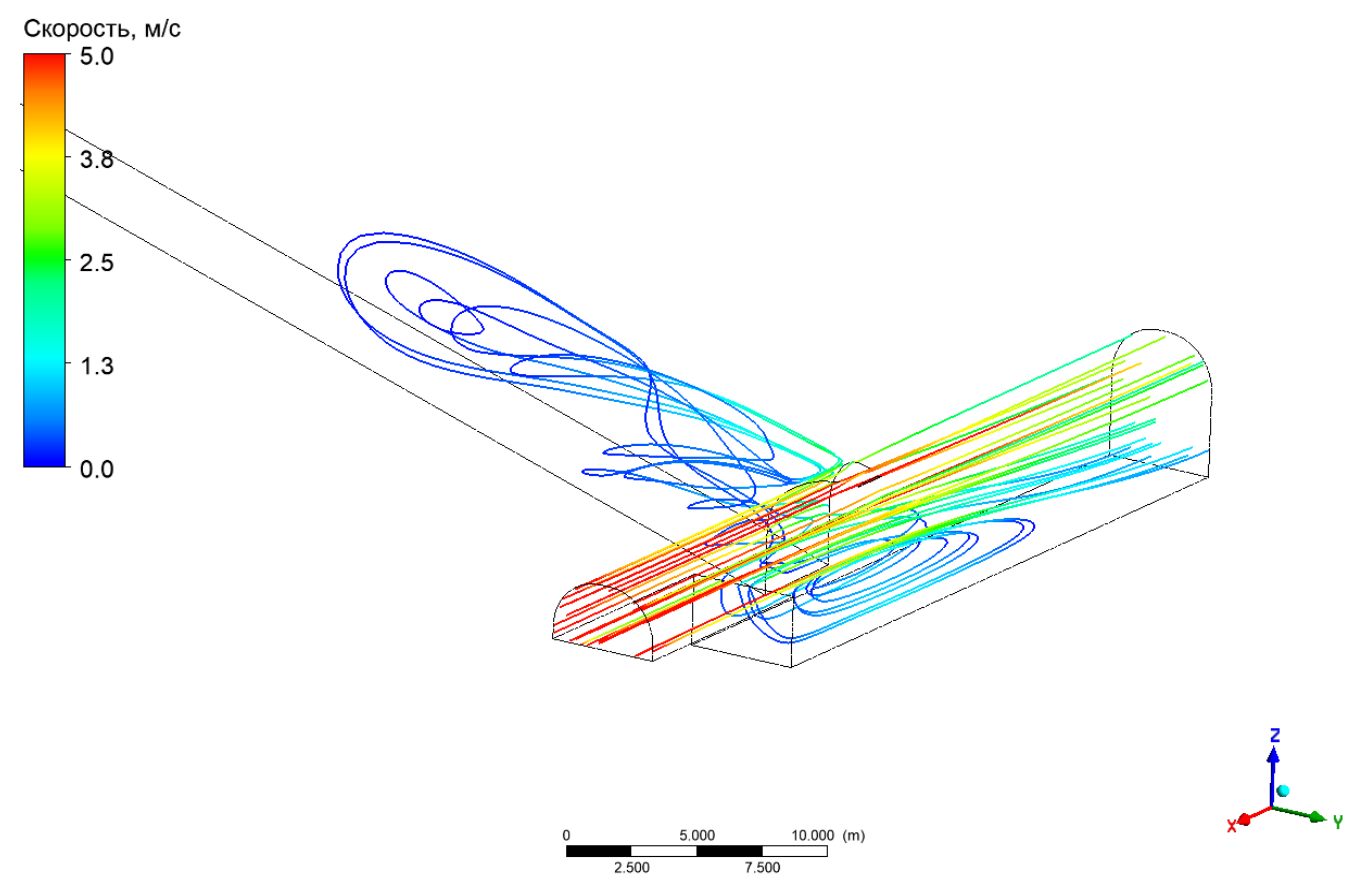

Рис. 2. Линии тока воздуха на участке сопряжения сквозной и тупиковой горных выработок 


\section{Результаты исследования образцов горных пород}

Отобранные образцы горных пород были исследованы на предмет образования продуктов окислительных реакций.

В результате исследований установлено, что сульфидная руда химически неустойчива и начинает вступать в реакцию при взаимодействии с атмосферным влажным воздухом. Особенно активно окисление происходит при формировании (эксплозивных) трещин в руде целиков или ее дезинтеграции до мелкообломочных фракций (штыба). Образование гидроксидов и сульфатов происходит с поглощением кислорода, что актуально для непроветриваемых выработок. Присутствие большого числа сульфатов магния, кальция, железа и никеля может говорить о том, что окисление руд сопровождается выделением не сернистого газа, а серной кислоты, что объясняет миграцию соединений железа в лужи и кислый состав рудничных вод.

\section{Результаты бактериологических исследований}

В отобранных образцах горных пород, шахтных вод специалистами Института экологии и генетики микроорганизмов УрО РАН произведены микробиологические исследования. Результаты исследований представлены на рисунке 3.

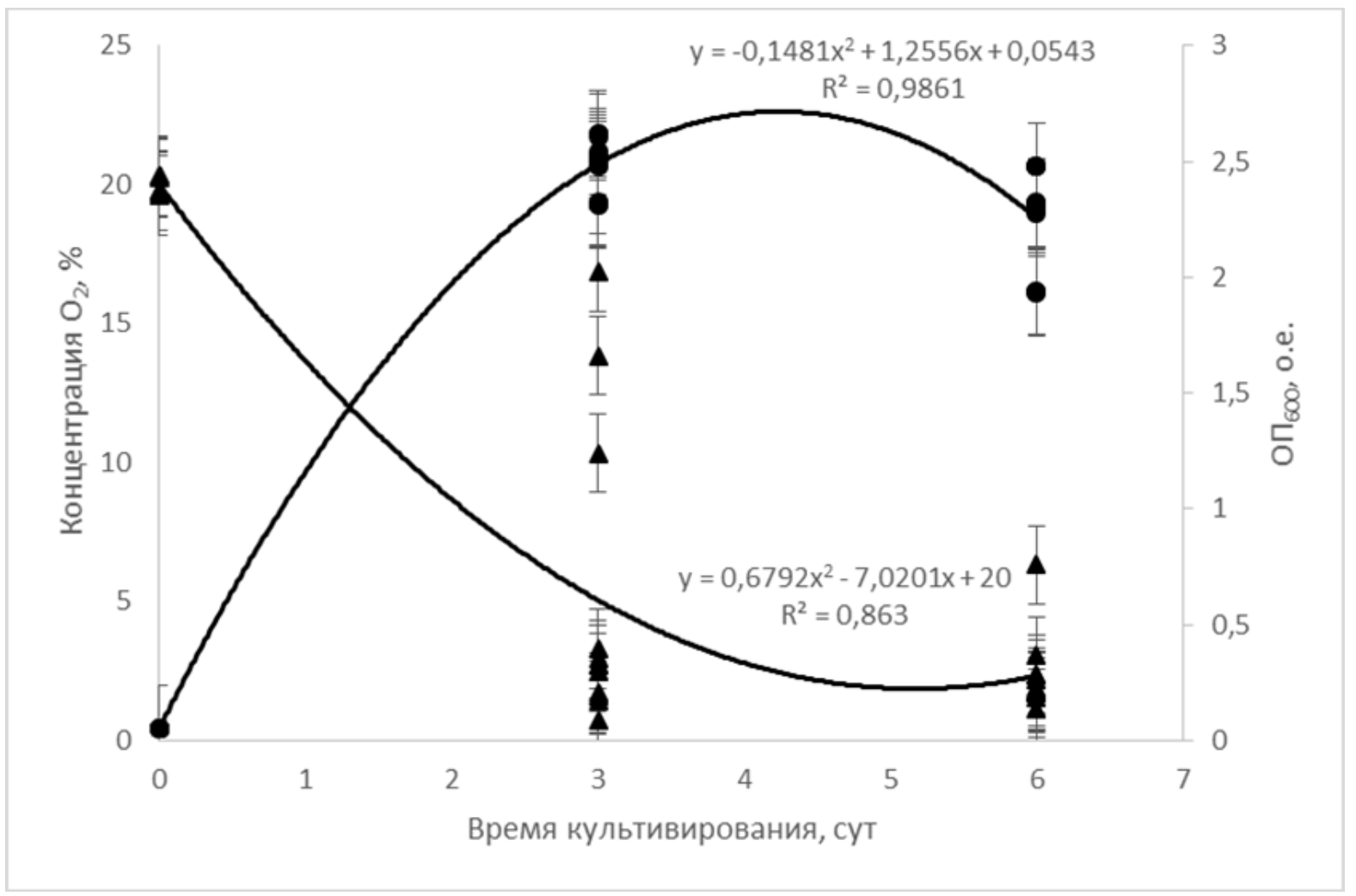

Рис. 3. Рост микроорганизмов и поглощение кислорода воздуха в модельном эксперименте

В результате проведенных исследований установлено, что на поверхности образцов породы из горной выработки присутствуют гетеротрофные и олиготрофные микроорганизмы, способные активно расти как при условиях активного воздухообмена, так и в условиях отсутствия притока кислорода. Снижение концентрации кислорода в воздухе приводит к замедлению процессов жизнедеятельности микроорганизмов.

Количество обнаруженных бактерий свидетельствует о том, что они не оказывают существенного влияния на окислительные процессы сульфидных руд. 


\section{Выводы по результатам исследований}

Сульфидные руды рассматриваемого месторождения являются склонными к окислению. Условия для интенсификации окислительных процессов создаются за счет следующих факторов:

- образование систем микротрещин в рудном массиве вблизи отрабатываемых камер в результате ведения буровзрывных работ;

- повышение влажности и температуры воздуха вследствие ведения закладочных работ;

- проникновение влажного и теплого воздуха в систему микротрещин.

Проведенные исследования образцов горных пород с места несчастного случая имеют следы свежего окисления.

Химический процесс окисления ускоряется и становится биохимическим за счет действия бактерий, обнаруженных в исследуемой горной выработке.

Интенсивное окисление сульфидных руд происходит с поглощением кислорода воздуха. Выработка является непроветриваемой, что подтверждается натурными исследованиями и математическим моделированием. Расстояние от устья выработки, на которое свежий воздух поступает из сквозной выработки за счет диффузионных процессов, не превышает 30 м. Остальная часть выработки, включая зону несчастного случая, не имеет воздухообмена с рудничной вентиляционной сетью. Таким образом, в выработке создались условия, при которых в результате биохимической реакции окисления сульфидных руд произошло уменьшение содержания кислорода.

Окисление сульфидных руд может происходить по двум сценариям:

- с образованием сернистого газа;

- без образования сернистого газа.

Проведенные исследования подтверждают сценарий окисления без образования сернистого газа: не обнаружено его следов ни в атмосфере горной выработки, ни в образцах воды. Математическое моделирование не позволило разработать гипотез полной его миграции из тупиковой горной выработки за счет разности плотностей или выноса с водой.

Окисление без образования сернистого газа происходит с образованием серной кислоты, что косвенно подтверждается исследованием образцов горных пород, кислой средой образцов воды, мировыми исследованиями биохимического окисления соединений железа и серы бактериями класса Acidithiobacillus ferrooxidans (и подобными). Следует отметить, что бактерии не выступают основной причиной окисления руд, а лишь ускоряют процесс химического окисления.

В результате вышеперечисленных процессов в горной выработке образовалась атмосфера, непригодная для дыхания ввиду низкого содержания кислорода. При этом в атмосфере не присутствовали ядовитые газы, что подтверждается исследованиями рудничной атмосферы места несчастного случая.

\section{Исследование выполнено при финансовой поддержке УрО РАН в рамках научного проекта № 18-5-5-5.}

\section{БИБЛИОГРАФИЧЕСКИЙ СПИСОК}

1. Федеральные нормы и правила в области промышленной безопасности «Правила безопасности при ведении горных работ и переработке твердых полезных ископаемых». Вып. 78: утв. 11.12.2013, № 32935. - М.: ЗАО НТЦ ПБ, 2016. - 276 с. - (Документы межотраслевого применения по вопросам промышленной безопасности и охраны недр: сер. 03). 